\title{
A Compact High-Power Ultra-Wideband Bipolar Pulse Generator
}

\author{
Zhaoyang Wu $\mathbb{D}$, Wei Lu, Enyan Ding, Xiangyang Bao, Zhoubing Yang, and Falun Song
}

Science and Technology on High Power Microwave Laboratory, Institute of Applied Electronics, China Academy of Engineering Physics, Mianyang 621900, China

Correspondence should be addressed to Falun Song; songfalun@caep.cn

Received 27 July 2021; Accepted 25 September 2021; Published 16 October 2021

Academic Editor: Tao Shao

Copyright $(\subset) 2021$ Zhaoyang Wu et al. This is an open access article distributed under the Creative Commons Attribution License, which permits unrestricted use, distribution, and reproduction in any medium, provided the original work is properly cited.

\begin{abstract}
A compact high-power ultra-wideband bipolar pulse generator based on a modified Marx circuit is designed, which is mainly composed of a primary power supply, Marx generator, sharpening and cutoff subnanosecond spark gap switches, and coaxial transmission lines. The Marx generator with modified circuit structure has thirty-two stages and is composed of eight disk-like modules. Each module consists of four capacitors, two spark gap switches, four charging inductors, and a mechanical support. To simplify the design of the charging structure and reduce the number of switches, four groups of inductors are used to charge the capacitors of the Marx generator, two of which are used for positive voltage charging and the other two for negative voltage charging. When the capacitor of each stage is charged to $35 \mathrm{kV}$, the maximum output peak voltage can reach $1 \mathrm{MV}$ when the Marx generator is open circuit. The high-voltage pulse generated by the Marx generator charges the transmission line and forms a bipolar pulse through sharpening and cutoff switches. All transmission lines used for bipolar pulse generation have an impedance of $10 \Omega$. When the $950 \mathrm{kV}$ pulse voltage generated by the Marx generator is fed into the transmission line, the bipolar pulse peak voltage can reach $390 \mathrm{kV}$, the center frequency of the pulse is about $400 \mathrm{MHz}$, and the output peak power is about $15.2 \mathrm{GW}$.
\end{abstract}

\section{Introduction}

High-power ultra-wideband (UWB) electromagnetic pulse has the characteristics of high power, narrow pulse width, and wide spectrum. It can produce electromagnetic interference to electronic devices through back door coupling and is widely used in susceptibility research of electronic systems $[1,2]$ and security defense applications, such as the vehicle stopping system [3]. In addition, due to the characteristics of short time-domain pulse, high-power UWB electromagnetic pulse is also widely used in biological effects research $[4,5]$ and the radar target identification technique [6-8]. There are two kinds of UWB electromagnetic pulse, one is monopole pulse and the other is bipolar pulse. The energy of monopole pulse is mainly concentrated in the lowfrequency part and the radiation efficiency is low, while the radiation efficiency of bipolar pulse is high because it has no DC component. Generally, there are two kinds of highvoltage sources for driving bipolar pulses. One is the Tesla transformer, for example, the Sinus-type ultra-wideband system developed by the Institute of High Current
Electronics (HCEI) [9-12], and RADAN series developed at the Institute of Electrophysics [13]. The other is to use the Marx generator to generate high-voltage pulse for driving bipolar pulse [14-17]. According to the published literature, the volume and weight of $10 \mathrm{GW}$ bipolar pulse generators are relatively large, which limits the further application of the system.

In this paper, a compact high-power UWB bipolar pulse generator is developed based on a modified circuit structure Marx generator. The structure Marx generator consists of 32 stages, including 8 disk-shaped modules, and each module contains four submodules. The structure combines ring and line structure. The disk-shaped modules are connected in a straight line, and each submodule is connected in a ring. Compared with the "linear" or "Z"-type Marx generator [18], the modified structure is greatly shortened in length. Compared with the bipolar pulse generated by Blumlein line [9], the bipolar pulse generated by a single line is simpler in structure and easier in insulation design and debugging under higher-power conditions (especially when the power exceeds $10 \mathrm{GW}$ ). 


\section{System Composition}

The high-power bipolar pulse generation system mainly consists of an integrated charging power supply, a modified structure Marx generator, and a bipolar pulse generator. Each subsystem is connected by a flange. The cavity of the Marx generator is filled with gas $\mathrm{SF}_{6}$ of $0.32 \mathrm{MPa}$. The system is a cylindrical structure with a total length of about $1.8 \mathrm{~m}$ (without load), maximum diameter of $0.4 \mathrm{~m}$, and total weight of only $200 \mathrm{~kg}$. The structure of the bipolar pulse generation system is shown in Figure 1.

The charging power supply charges the Marx generator through a full bridge circuit, high-frequency transformer, and rectifiers. The maximum output peak voltage of the Marx generator is more than $1 \mathrm{MV}$. The high-voltage "wide" pulse input by the Marx generator is compressed into a monopole "narrow" pulse through a transmission line and a sharpening switch, and then, the bipolar pulse is generated by a ring cutoff switch and another sharpening switch.

The experimental results show that the test waveform of bipolar pulse is consistent with the simulation waveform of PSPICE software. The center frequency of the bipolar pulse is about $400 \mathrm{MHz}$, and the output peak power is more than $15 \mathrm{GW}$.

\section{High-Voltage Pulse Generation}

3.1. Structure of the Marx Generator. The high voltage to drive the bipolar pulse is generated by using a modified Marx generator. The capacitance of each stage is $6 \mathrm{nF}$, which is composed of twelve $50 \mathrm{kV} / 0.5 \mathrm{nF}$ ceramic capacitors in parallel. The disk module is $40 \mathrm{~mm}$ thick with an interval of $35 \mathrm{~mm}$ between the two adjacent disk modules. Eight disk modules are stacked in series; the output of the former module is connected to the input of the latter module in two adjacent modules. The total length of the Marx core is $600 \mathrm{~mm}$. When the Marx generator is operating, the discharge current spirals forward and passes through each sector capacitor bank in turn. The structure of the Marx generator is shown in Figure 2.

3.2. Circuit Structure of the Marx Generator. The circuit principle of the 8-stage Marx generator is shown in Figure 3, and all discharge switches are self-breakdown spark gap. Different from the Marx generator charged by positive and negative voltages $[19,20]$, the modified Marx generator uses four charging channels, two of which are positive voltage and the other two are negative voltage. The advantage of this charging circuit topology is that the design of charging circuit structure is simplified and the cross of positive and negative charging inductors is avoided.

3.3. Constant Current Charging Power Supply. To make the system compact, the charging power supply was integrated to the end of the Marx generator. The charging power supply adopts the L-C constant current resonant charging mode. The control circuit outputs 2 PWM (Pulse Width Modulation) signals and drives the IGBT switch to turn the DC voltage into a $20-\mathrm{kHz}$ periodic square voltage. Then, the periodic square wave voltage changes into $\pm 35 \mathrm{kV}$ high voltage after passing through the high-frequency transformer, rectifier circuit, protection circuit, etc. The circuit diagram is shown in Figure 4. Since a Marx generator module needs two positive voltage inputs and two negative voltage inputs, the isolated inductor is used to separate the positive voltage and negative voltage into two channels, as shown in the output section of Figure 4.

3.4. Spark Gap Switch. The discharge switch is a key component of the Marx generator, and its characteristics directly affect the working performance of the generator. The requirements of the discharge switch are short conduction time, good working stability, and small time-delay jitter. Since all switches of the generator are overvoltage selfbreakdown, continuous clearance adjustment is considered in the switch design for the convenience of debugging. The spark gap switch adopts a planar cylindrical electrode, the electric field is evenly distributed, and the switch spacing is continuously adjusted by thread. The switch electrode with a diameter of $20 \mathrm{~mm}$ is made of stainless steel. To prevent the corona phenomenon, the electrode edge has a smooth transition of the fillet. The switches are placed in two rows in the center of the capacitor disk module, with no shielding between them. The ultraviolet light rays generated during switch discharge illuminate each other, accelerate the switch conduction, and facilitate the erect of the Marx generator. The structure and layout of the switches are shown in Figure 5.

3.5. Design of the Isolation Inductor. When the Marx generator is charged, the current change rate $\mathrm{dI} / \mathrm{dt}$ is very small. So, the isolation inductor is approximately a complete conductor, and the charging efficiency is approximately $100 \%$. The isolation inductance does not affect the charging time and efficiency, while, when the Marx generator is discharged, the inductance of the isolation inductor affects the output peak voltage of the Marx generator.

Figure 6 shows the variation of output peak voltage of Marx with different isolation inductors (load resistance $R=500 \Omega$ ). As the inductance increases, the output peak voltage increases too, and the voltage waveform changes from an underdamped state to overdamped state. When the inductance reaches $10 \mu \mathrm{H}$, the output voltage differs a little from that of $100 \mu \mathrm{H}$. Considering the need of a compact design of the system, the isolation inductance is taken as $20 \mu \mathrm{H}$. The inductor adopts a hollow spiral structure, which is made by wrapping an enameled wire around an insulated cylinder. The length of the inductor is about $75 \mathrm{~mm}$, which ensures no surface breakdown under the environment of high-voltage $\mathrm{SF}_{6}$ gas.

\section{High-Power Bipolar Pulse Generation}

The high-power bipolar pulse generation circuit is shown in Figure 7 . Because the output voltage front of the Marx generator is about tens of nanoseconds, it cannot be used to 


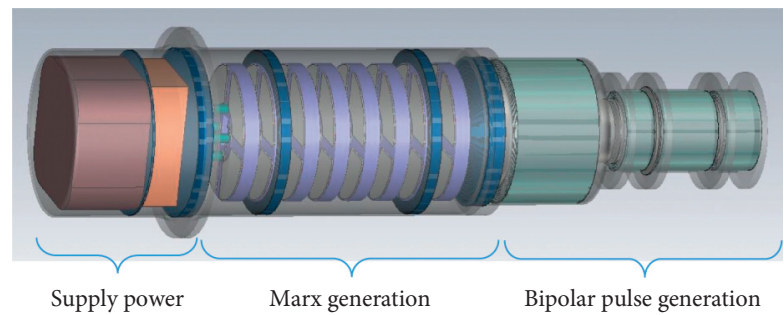

Figure 1: Structure diagram of the high-power bipolar pulse generation system excluding 10-ohm load.
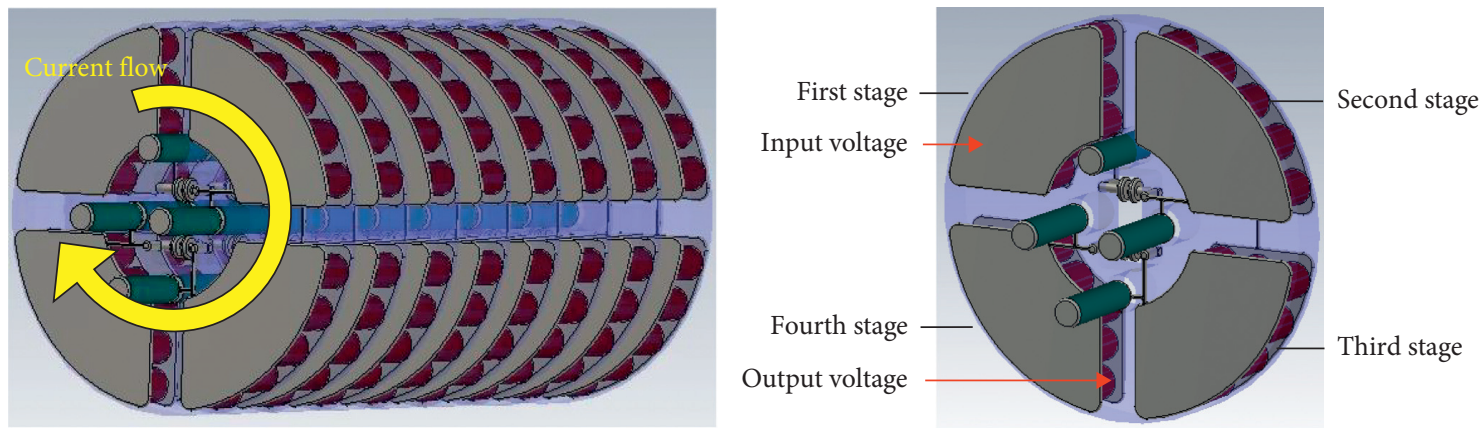

Figure 2: The structure diagram of the 32-stage Marx generator (as shown in the left figure), which consists of 8 disk modules, and each module contains four stages (as shown in the right figure).

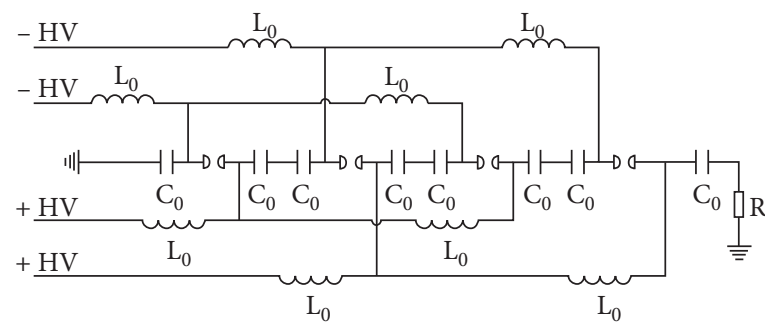

FIgURE 3: The circuit of the 8-stage Marx generator with a four-group charging loop.

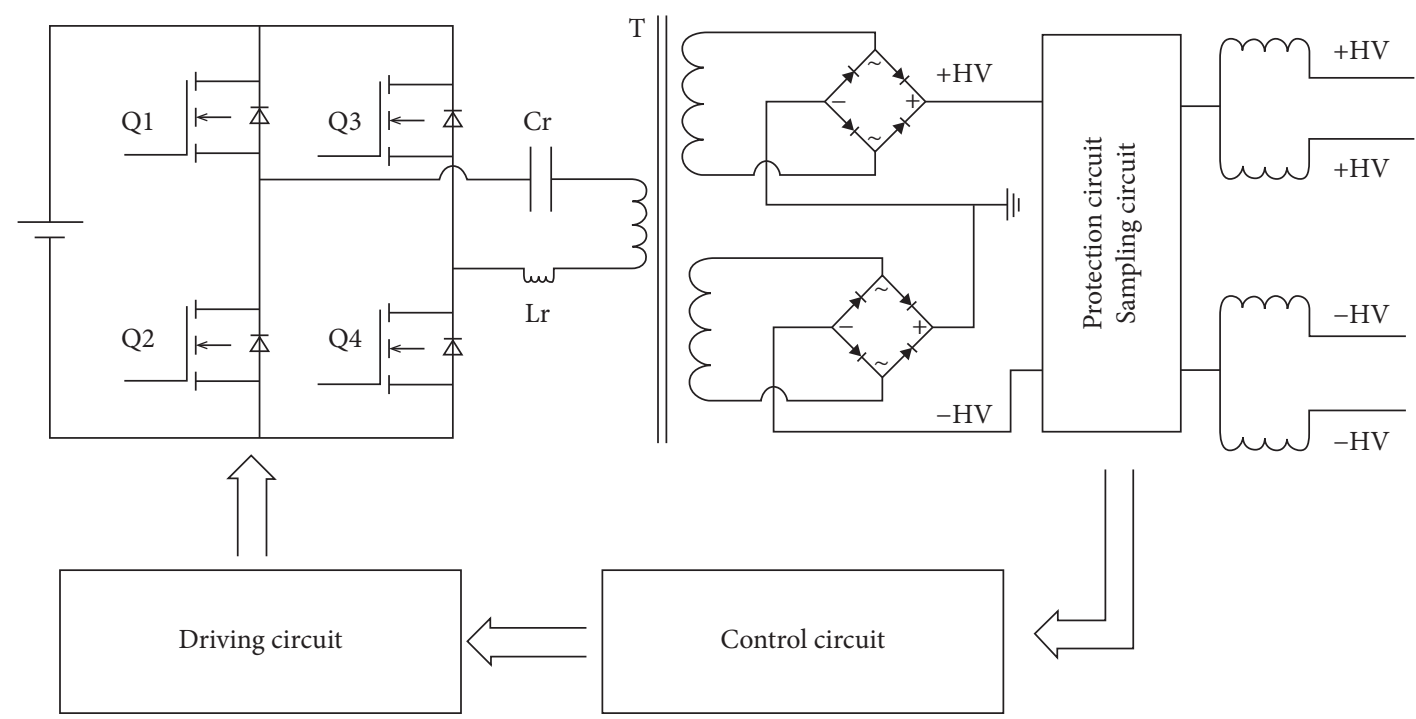

FIGURE 4: The circuit diagram of constant current charging power supply. 


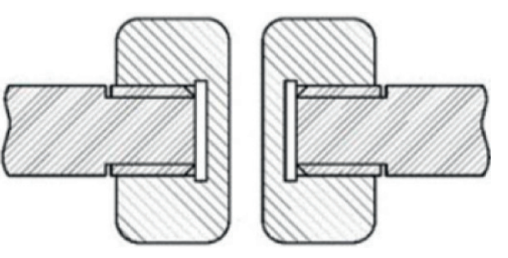

(a)

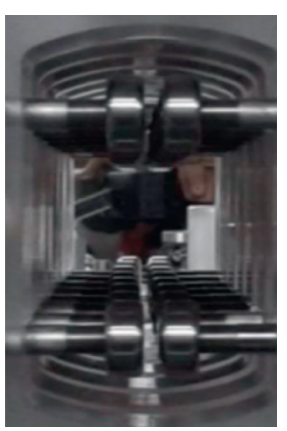

(b)

FIGURE 5: Switch structure (a) and layout (b).

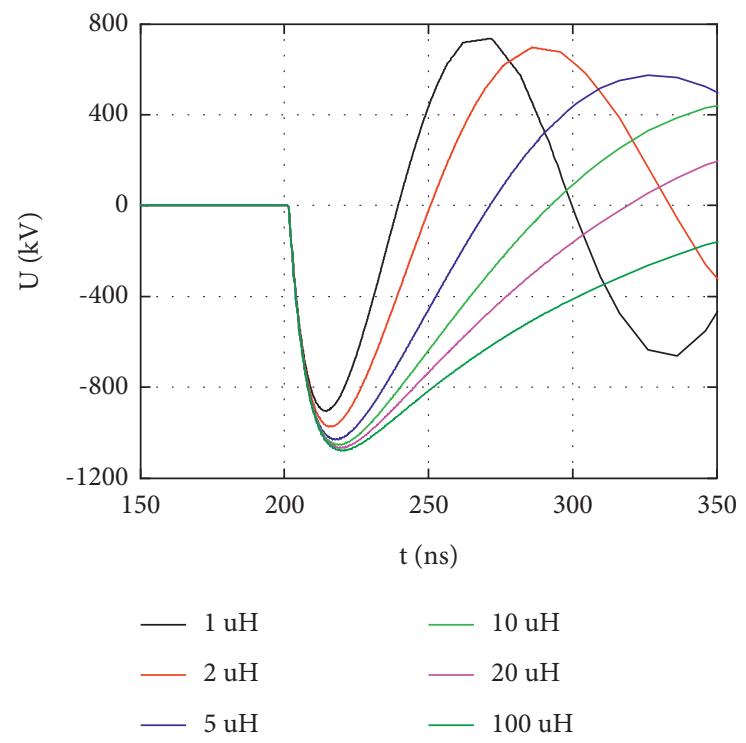

FIGURE 6: Influence of isolation inductance on the output voltage waveform of the Marx generator.

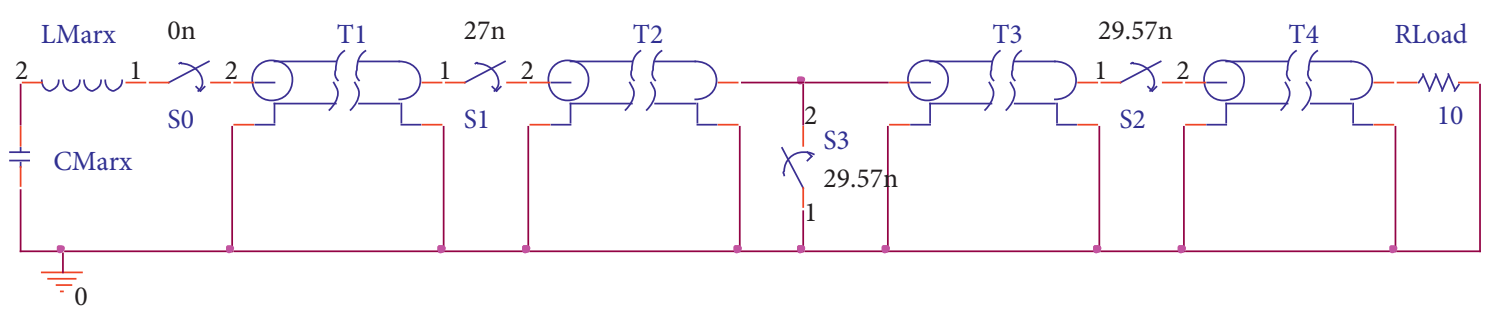

FIGURE 7: Circuit of high-power bipolar pulse generation.

generate a bipolar pulse directly, so it needs to be compressed. When the switch S0 is on, the Marx generator charges the transmission line $\mathrm{T} 1$. When the charging voltage reaches or approaches the maximum voltage, the switch $S 1$ is on, and the transmission line $\mathrm{T} 1$ charges $\mathrm{T} 2$ and $\mathrm{T} 3$. When the voltage pulse reaches the switch S2, the switch S2 does not conduct, resulting in total reflection. When the reflected voltage reaches the ground switch S3, the switch S2 and switch S3 conduct simultaneously (the switch S3 is shortcircuit total reflection, and the voltage polarity is reversed), forming a bipolar pulse on the transmission line T4.
According to the principle of bipolar pulse generation, Pspice software was used to simulate the generation of bipolar pulse. $L_{\text {marx }}$ is the sum of the equivalent inductance of Marx and the connection inductance between Marx and T1, and the total inductance is $5 \mu \mathrm{H}$. $C_{\operatorname{marx}}$ is the equivalent capacitance of Marx, and the value is $0.1875 \mathrm{nF}$. The characteristic impedances of transmission lines T1, T2, T3, and T4 are all $10 \Omega$, and the electrical lengths are $1 \mathrm{~ns}, 0.3 \mathrm{~ns}$, $0.8 \mathrm{~ns}$, and $10 \mathrm{~ns}$, respectively. $R_{\text {Load }}$ is the resistive load with a resistance of $10 \Omega$. The simulation results are shown in Figure 8. After the Marx generator charged with $\pm 35 \mathrm{kV}$ is 

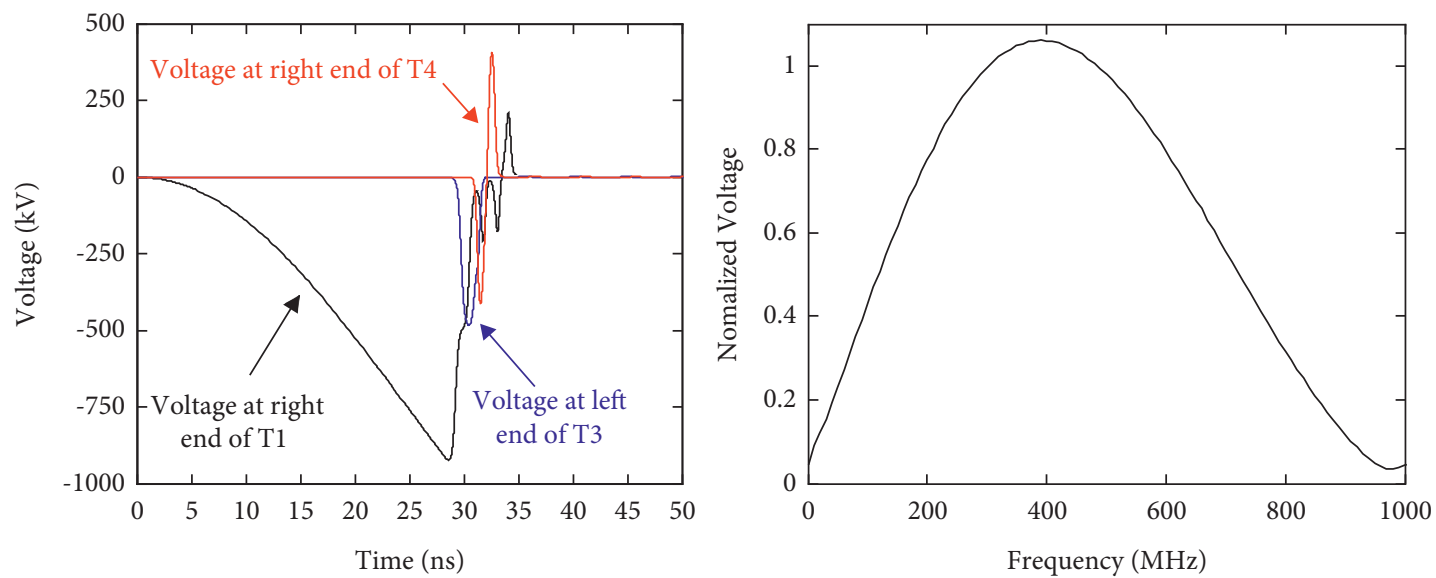

FIGURE 8: Simulated time-domain voltage waveform and bipolar pulse frequency-domain waveform.

discharged, a $920 \mathrm{kV}$ voltage pulse was obtained on $\mathrm{T} 1$ after about $27 \mathrm{~ns}$. At this moment, switch $\mathrm{S} 1$ is on, and transmission line $\mathrm{T} 1$ charges to T2 and T3. After 2.57 ns, switch S2 and $\mathrm{S} 3$ are on at the same time, and a bipolar pulse of about $400 \mathrm{kV}$ is obtained on the T4, with an output power of about $16 \mathrm{GW}$ and a central frequency of $400 \mathrm{MHz}$.

The structure of the bipolar pulse generator is predicted in Figure 9. The device adopts a coaxial transmission line structure, and the sharpening switches S1 and S2 are ring switches, which are installed on the inner conductor of the transmission line. The gap of switches S1, S2, and S3 is $10 \mathrm{~mm}, 2.2 \mathrm{~mm}$, and $2 \mathrm{~mm}$, respectively. The switch cavities S1, S2, and S3 are filled with high-pressure nitrogen of $4 \mathrm{MPa}, 7 \mathrm{MPa}$, and $7 \mathrm{MPa}$, respectively.

When the ring switch breaks down, it can form multiple conductive channels, which can effectively reduce the inductance of the switch and accelerate the conduction speed. The ground switch S3 is also a ring structure, which is installed on the outer cylinder of the transmission line. Sharpening switch S1, S2, and ground switch S3 are made of stainless steel. Each switch has an independent switch cavity to facilitate air pressure adjustment. The switch cavity can withstand pressure greater than $10 \mathrm{MPa}$. The inner and outer conductors of the transmission lines $\mathrm{T} 1, \mathrm{~T} 2, \mathrm{~T} 3$, and $\mathrm{T} 4$ are also made of stainless steel. The outer conductor diameter is $200 \mathrm{~mm}$, and the inner and outer conductors are filled with plexiglass as insulation support. The relative dielectric constant of plexiglass is 2.3 .

\section{Experimental Results}

The pulse voltage signal in the process of bipolar pulse generation is detected by the capacitor voltage divider, and its bandwidth can reach $2 \mathrm{GHz}$. The capacitor voltage divider is set on the inner wall of the outer conductor of the transmission lines $\mathrm{T} 1, \mathrm{~T} 3$, and $\mathrm{T} 4$, and their voltage ratio is $1271.4,1095.8,1155$, respectively. The signal of the capacitor voltage divider is transmitted to the oscilloscope through a $50 \mathrm{~dB}$ attenuator and a $30 \mathrm{~m}$ coaxial cable whose attenuation coefficient is about 1.4 at the frequency of $400 \mathrm{MHz}$. The bandwidth of the oscilloscope (Lecroy waverunner 8254 M) is $2.5 \mathrm{GHz}$. The voltage waveforms obtained by the capacitor voltage divider on transmission lines $\mathrm{T} 1$ and $\mathrm{T} 3$ are shown in Figure 10. After the Marx generator charges the transmission line $\mathrm{Tl}$ for about $27 \mathrm{~ns}$, the voltage on the transmission line $\mathrm{T} 1$ is about $950 \mathrm{kV}$ (the measured value of the oscilloscope is $1.69 \mathrm{~V})$. At this time, the switch S1 is on, and a monopole pulse with a pulse width of about $2 \mathrm{~ns}$ and amplitude of about $509 \mathrm{kV}$ (the measured value of the oscilloscope is $1.05 \mathrm{~V}$, which is the average value of 10 recorded data) is obtained on the transmission line T3.

After the monopole pulse is reflected by switches S2 and S3, a high-power bipolar pulse is generated on the transmission line T4. The experimental bipolar pulse waveform and simulated waveform are shown in Figure 11. As can be seen from the figure, the generated bipolar pulse width is about $3.5 \mathrm{~ns}$, the amplitude is $390 \mathrm{kV}$, and the output power is $15.2 \mathrm{GW}$. The experimental waveform is consistent with the simulated waveform.

Since the electric length of transmission line $\mathrm{T} 1$ is $1 \mathrm{~ns}$, its capacitance is about $100 \mathrm{pF}$. When the charging voltage on $\mathrm{T} 1$ is $950 \mathrm{kV}$, the input energy on $\mathrm{T} 1$ is $45.1 \mathrm{~J}$. The power obtained on $10-\mathrm{ohm}$ load is $15.2 \mathrm{GW}$, and the half width of the bipolar pulse waveform is about $1.75 \mathrm{~ns}$, as shown in Figure 11. Through integral calculation, the output energy of the bipolar pulse generator is about $26.6 \mathrm{~J}$, so the energy efficiency of the bipolar pulse generator is about $59 \%$.

An experimental study on the repetition-rate characteristics of the bipolar pulse generator was carried out by replacing the resistive 10 -ohm load with a high-power UWB antenna. The radiation system operated continuously for one minute at a repetition rate of $100 \mathrm{~Hz}$ and operated stably. Figure 12 shows the far-field radiation waveforms under the repetition rate operation condition. The cumulative number of operating pulses of the system has exceeded $10^{5}$.

Due to the use of $\mathrm{SF}_{6}$ insulating gas, its poor thermal conductivity and ionization products are the main reasons for the performance degradation or failure of the bipolar pulse generation system. When $\mathrm{SF}_{6}$ gas is discharged and ionized, it will produce toxic or corrosive gases, such as $\mathrm{SO}_{2}$, $\mathrm{H}_{2} \mathrm{~S}$, and HF. These ionized gases will also seriously reduce the insulation performance of $\mathrm{SF}_{6}$ and affect the service life 


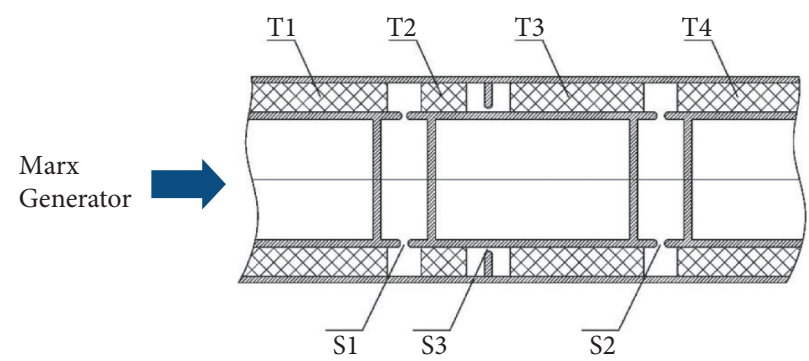

Figure 9: Structure diagram of the bipolar pulse generator.

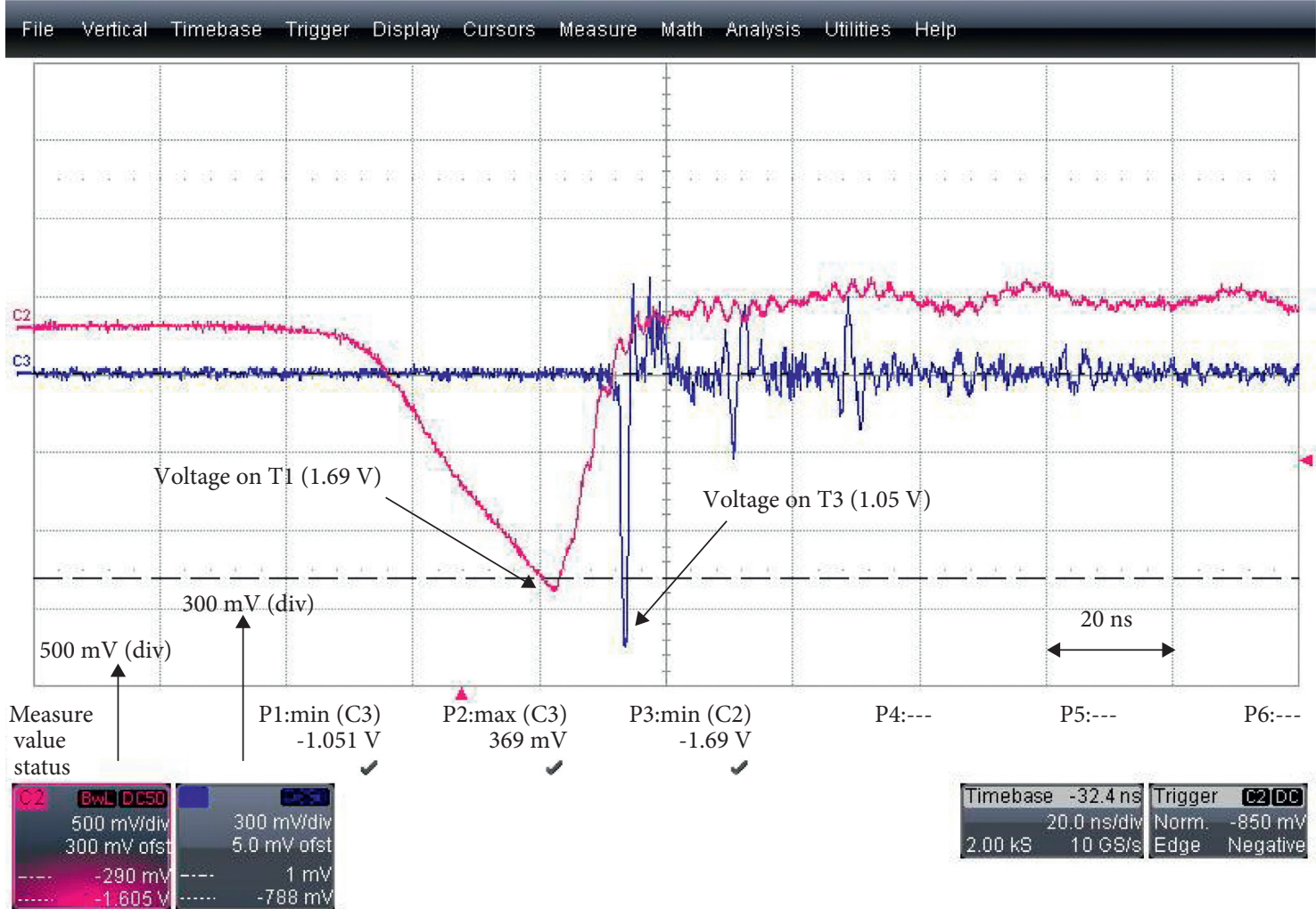

Figure 10: Experimental voltage waveforms on transmission lines T1 and T3.

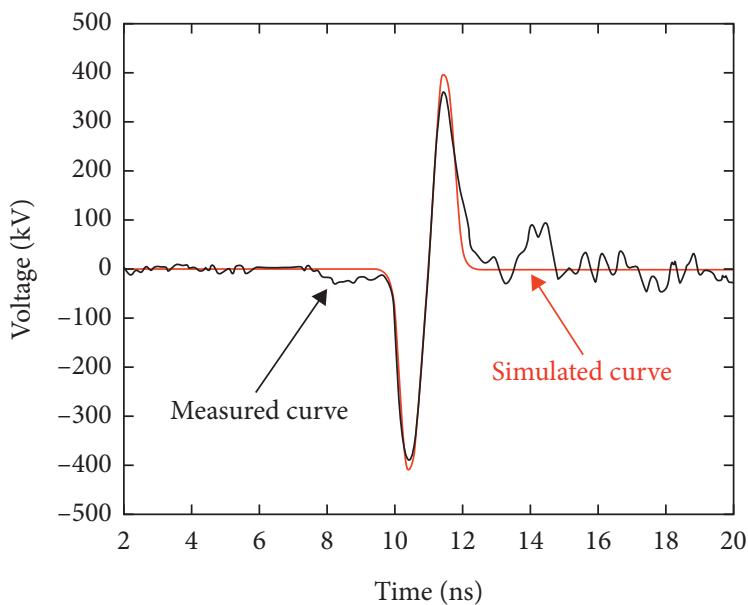

Figure 11: Comparison of the experimental bipolar pulse waveform and the simulated waveform. 


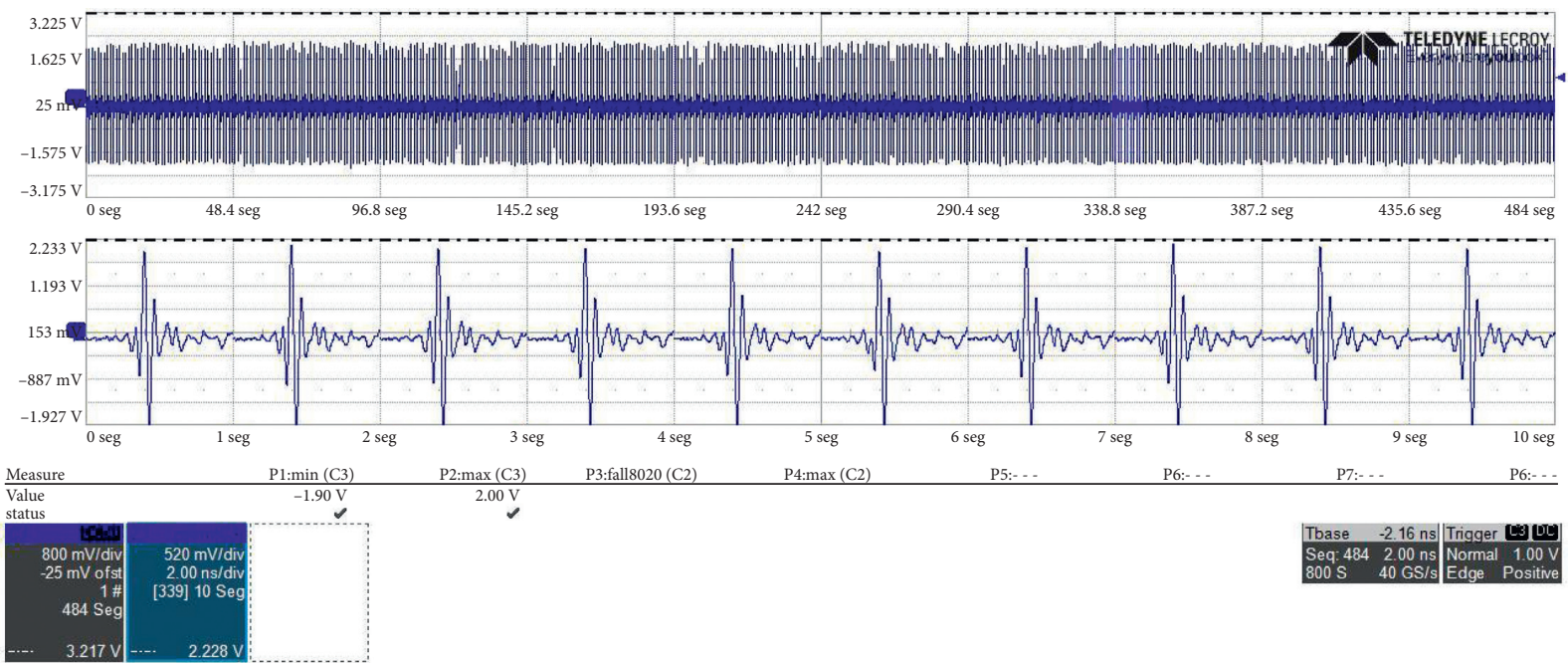

FIgURE 12: Far-field radiation waveforms of the bipolar pulse generator at $100 \mathrm{~Hz}$ repetition rate.

of the generator. After the experiment, the ionized $\mathrm{SF}_{6}$ gas needs to be discharged into a special collection container through a pipe.

\section{Conclusions}

In this paper, a high-power bipolar pulse generation system based on a modified Marx generator is designed; its size is $\varphi 400 \mathrm{~mm} \times 1800 \mathrm{~mm}$, and weight is about $200 \mathrm{~kg}$. The modified structure Marx generator consists of 32 stages, including 8 disk-shaped modules, and each module contains four submodules. The structure combines ring and line structure. The disk-shaped modules are connected in a straight line, and each submodule is connected in a ring. Compared with the "linear" or " $Z$ "-type Marx generator, the modified structure is greatly shortened in length. The total length of the Marx core is only $600 \mathrm{~mm}$, with an output voltage pulse of more than $1 \mathrm{MV}$.

The bipolar pulse generator consists of four $10 \Omega$ lowimpedance coaxial transmission lines, two sharpening switches, and a cutoff switch. Compared with the bipolar pulse generated by Blumlein line, the bipolar pulse generated by the single line described in this paper is simpler in structure and easier in insulation design and debugging under higher power conditions, especially when the power exceeds $10 \mathrm{GW}$.

The simulation and experimental results show that a bipolar pulse with a width of about $3.5 \mathrm{~ns}$, voltage of $390 \mathrm{kV}$, and output power of more than $15 \mathrm{GW}$ was obtained on a 10 ohm transmission line. The experimental results are consistent with the simulation results. The bipolar pulse generator with a UWB antenna has been tested, and it can run steadily for one minute under the condition of $100 \mathrm{~Hz}$ repetition rate, and the cumulative lifetime is more than $10^{5}$ pulses.

\section{Data Availability}

The data used to support the findings of this study are available upon request.

\section{Conflicts of Interest}

The authors declare no conflicts of interest.

\section{References}

[1] D. Nitsch, M. Camp, F. Sabath, J.-L. terHaseborg, and H. Garbe, "Susceptibility of some electronic equipment to HPEM threats," IEEE Transactions on Electromagnetic Compatibility, vol. 46, no. 3, pp. 380-389, 2004.

[2] F. Sabath and S. Potthast, "Tolerance values and the confidence level for high-altitude electromagnetic pulse (HEMP) field tests," IEEE Transactions on Electromagnetic Compatibility, vol. 55, no. 3, pp. 518-525, 2013.

[3] K. Hong and S. Braidwood, "Stopping car engines using high power electromagnetic pulses," in Proceedings of the International Conference on Electromagnetics in Advanced Applications, pp. 378-381, Sydney, Australia, September 2010.

[4] Y. G. Shckorbatov, N. N. Kolchigin, and V. N. Pasiuga, "Biological effects of ultrawideband radiation," in Proceedings of the International Conference on Ultrawideband and $\mathrm{Ul}$ trashort Impulse Signals, pp. 192-194, Sevastopol, Ukraine, September 2010.

[5] T. Schunk, F. Bieth, S. Pinguet, and P. Delmote, "Penetration and propagation into biological matter and biological effects of high-power ultrawideband pulses: a review," Electromagnetic Biology and Medicine, vol. 35, no. 1, pp. 84-101, 2016.

[6] R. Negrier, M. Lalande, J. Shalaby et al., "High-PRF UWB optoelectronic radar system: a clean-type algorithm to overcome depth limitation," IEEE Transactions on Antennas and Propagation, vol. 64, no. 3, pp. 1080-1088, 2016.

[7] R. Sadli, C. Tatkeu, K. Hamidoun, Y. El Hillali, and A. Rivenq, "UWB radar recognition system based on HOS and SVMs," IET Radar, Sonar \& Navigation, vol. 12, no. 10, pp. 1137-1145, 2018.

[8] R. Salman1, T. Schultze1, and M. Janson, "Robust UWB radar object recognition," in Proceedings of the IEEE International RF and Microwave Conference, pp. 399-403, Kuala Lumpur, Malaysia, December 2008.

[9] Y. A. Andreev, A. M. Efremov, V. I. Koshelev et al., "A source of high-power pulses of elliptically polarized ultrawideband 
radiation," Review of Scientific Instruments, vol. 85, no. 10, Article ID 104703, 2014.

[10] A. M. Efremov, V. I. Koshelev, V. V. Plisko, and E. A. Sevostyanov, "A high-power synthesized ultrawideband radiation source," Review of Scientific Instruments, vol. 88, no. 9, Article ID 094705, 2017.

[11] V. P. Gubanov, A. M. Efremov, V. I. Koshelev et al., "A source of high-power pulses of ultrawideband radiation with a nineelement array of combined antennas," Instruments and Experimental Techniques, vol. 60, no. 2, pp. 213-218, 2017.

[12] A. M. Efremov, V. I. Koshelev, and V. V. Sevostyanov, "A high-power source of ultrawideband pulses of synthesized radiation," Instruments and Experimental Techniques, vol. 62, no. 1, pp. 33-41, 2019.

[13] M. I. Yalandin and V. G. Shpak, "Compact high-power subnanosecond repetitive-pulse generators (review)," Instruments and Experimental Techniques, vol. 44, no. 3, pp. 285-310, 2001.

[14] J. R. Mayes, C. W. Hatfield, and M. G. Mayes, "A compact high power wideband system," in Proceedings of the IEEE International Power Modulator and High Voltage Conference, pp. 612-616, Atlanta, GA, USA, May 2010.

[15] L. Pecastaing, B. Cadilhon, and T. Reess, "A 250KV-300PS$350 \mathrm{HZ}$ Marx generator as source for an UWB radiation system," in Proceedings of the IEEE International Pulsed Power Conference, pp. 51-56, Washington, DC, USA, June 2009.

[16] P. Delmote, J. P. Dupéroux, F. Bieth et al., "Performances of an ultra-compact, high-power, monocycle pulse former for WB and UWB applications," in Proceedings of the IEEE International Pulsed Power Conference, pp. 558-562, Chicago, IL, USA, June 2011.

[17] S. Pinguet, J.-P. Dupéroux, P. Delmote, F. Bieth, and R. Bischoff, "Short-pulse Marx generator for high-power microwave applications," IEEE Transactions on Plasma Science, vol. 41, no. 10, pp. 2754-2757, 2013.

[18] F. Lassalle, A. Morell, A. Loyen et al., "Development and test of a $400-\mathrm{kV}$ PFN Marx with compactness and rise time optimization," IEEE Transactions on Plasma Science, vol. 46, no. 10, pp. 3313-3319, 2018.

[19] F. Song, F. Li, and B. Zhang, "Recent advances in compact repetitive high-power Marx generators," Laser and Particle Beams, vol. 37, no. 1, pp. 110-121, 2019.

[20] F. Song, B. Zhang, C. Li et al., "Development and testing of a three-section pulse-forming network and its application to Marx circuit," Laser and Particle Beams, vol. 37, no. 4, pp. 408-414, 2019. 